HOW DOES LABOUR MARKET HISTORY INFLUENCE THE ACCESS TO HIRING INTERVIEWS?

Emmanuel Duguet, Remi le Gall, YANniCK L'Horthy, PASCALE PetiT 
ISSN 2110-5472 


\title{
How does labour market history influence the access to hiring interviews? *
}

\author{
Emmanuel Duguet ${ }^{1,3}$, Rémi Le Gall ${ }^{2,3}$, Yannick L'Horty ${ }^{2,3}$ and Pascale Petit ${ }^{2,3}$ \\ ${ }^{1}$ Université Paris Est Créteil, ERUDITE (EA 437) \\ ${ }^{2}$ Université Paris Est Marne la Vallée, ERUDITE (EA 437) \\ ${ }^{3}$ FR TEPP CNRS 3435
}

September 2017

\begin{abstract}
We evaluate the effect of labour market history on the current probability to be invited to a hiring interview. We compare the effect of periods of unemployment, part-time job and short-term contracts. Correspondence tests were conducted for accountants and sales assistants. We estimate the discrimination components from the response rate of each candidate by the asymptotic least squares method. We find that men with a part time profile suffer discrimination in both professions. Other differences of treatment are specific: for accountants, we find that the probability of success decreases with the time spent in unemployment, while for for sales assistants the probability of success is smaller with a history of short term contracts.
\end{abstract}

JEL: C51, C93, J16, J24, J71.

Keywords: Labour market history, Unemployment, Part time job, Discrimination, Hiring, France.

${ }^{*}$ This study was carried out as part of a research agreement with the French national employment agency (Pôle emploi). It has benefited from comments by members of the scientific council of Pôle emploi and by François Aventur and Anita Bonnet. We also thank G.E. Birkelund, S. Baert and the participants to the Conference on "Hiring Discrimination: Measures, Moderators and Mechanisms" (Wäxjö, August 2017) for their helpful suggestions and comments. The usual disclaimer applies. Corresponding author: Emmanuel Duguet, Université Paris Est, Mail des Mèches, 61 avenue du Général de Gaulle, 94010 Créteil Cedex, France (emmanuel.duguet@u-pec.fr). 


\section{Introduction}

The French labour market entered its sixteenth semester of continuous decline in early 2016. The number of job seekers increased by 2.5 million, an upsurge of $80 \%$ since the beginning of the 2008 rise in unemployment. The unemployment rate reached $10.5 \%$, more than three percentage points higher than at the beginning of the crisis. In this context, the duration of unemployment has risen sharply and insecure employment positions have developed (involuntary part-time jobs, short-term contracts, unemployment).

Many studies indicate that the current occupation (employment, unemployment) influences the subsequent trajectory of people in the labour market (Givord, 2005; Fremigacci and Terracol, 2014; Fontaine and Rochut, 2014). Having a poor quality job can reduce the chances of getting a good job in the future. Therefore, the workers who have to take part time or short term jobs may face the risk to fall in a "bad job trap", while the workers who decline these job offers may face long term unemployment. The crisis would amplify the dualism of the labour market between stable (good) jobs and unstable (poor) jobs. This phenomenon has also been identified for decades as an unemployment persistence factor at the macroeconomic level (Blanchard and Summers, 1986). Dualism is the subject of renewed attention in the context of the Great Recession. In the United States, recent studies have shown that among workers who experienced 6 months of unemployment between 2008 and 2012, only 11\% have found a stable job 15 months later (Krueger et al., 2014). The chances of returning back to work are highly dependent on the time spent out of work, especially the first eight months of searching and when the local labour markets are in turmoil (Kroft et al., 2013). The crisis may well have reinforced this negative correlation between returning to work and the duration of unemployment (Kroft et al., 2014). It seems to have altered the cyclical properties of the American economy, making it less resilient to shocks.

Theoretically, the relationship between the current occupation and the subsequent trajectory in the labour market can be explained by human capital (Becker, 1994) and signalling (Spence, 1973). According to the first mechanism, employment is a vocational experience that alters human capital, modify the cognitive or non-cognitive abilities, like a person's motivation. According to the second mechanism, even when human capital is unchanged, having a bad job provides information that can be used by future recruiters as far as it can be interpreted as an employability or a productivity indicator. Contextual factors are also at play. The charac- 
teristics of the firm (size, line of business) will interfere with the signal sent by the candidate. The same signal can be received very differently from one professional domain to another. The current type of job also provides information on the worker's availability and an employer can balance employability and availability.

In practice it is difficult to distinguish a signalling effect from a human capital effect. The chances of exiting unemployment and getting a high quality job depend on many factors. Among them, it is particularly complicated to identify the specific effect of an individual's previous occupation or past duration of unemployment, both of which depend on the same factors. We must guard ourselves against selection and endogeneity biases. This is the subject of an extensive microeconometric literature, which applies duration models to the analysis of unemployment. It is even more difficult to break down this effect according to the mechanism at play, human capital or signalling. One solution for identifying the cause of discrimination is the use of laboratory experiments. Van Belle et al. (2017) find that a long unemployment period may be interpreted as a lack of motivation by the recruiters.

In order to assess the effect of labour market history, we need to control for human capital. An efficient way to control for it is to collect experimental data, since it allows for treating both the observable characteristics of the job applicants and unobservable heterogeneity. The first study that used an experimental method in order to measure the effects unemployment duration on the chances of obtaining a job was carried out in Switzerland in 1999 (Oberholzer-Gee, 2008). It has been followed by several studies on the American labour market (Kroft et al., 2013). These studies have found both human capital and signalling effects, a weakening in the chances of exiting unemployment after six months only. Birkelund, Heggebø and Rogstad (2017) find a negative effect of long-term unemployment in the Norwegian labour market, stronger for women. Baert and Verhaest (2016) reach a similar conclusion for the Belgian labour market, after one year in unemployment. However, some studies have made other findings. A study carried out in Sweden with the same type of method indicates that the effects of past employment and unemployment situations are rather insignificant compared to the current situation of the applicant (Eriksson and Rooth, 2011). Cahuc, Carcillo and Minea (2017) find that unemployment has no effect on a population of French high school drop-outs. We present the first study for experienced workers in France.

We have made a correspondence test in order to identify the effect of the past and current occupations on the chances to be invited to a hiring interview. We have selected two profes- 
sions with a tight labour market: accountants and sales assistant. Our applicants have five different profiles: long term contracts, short term contracts, short term unemployment, long term unemployment and part time jobs. We find that men with a part time profile suffer discrimination in both professions. For accountants, we find that the probability of success also decreases with the time spent in unemployment. For sales assistants, we find that a history of short term contracts reduces the chances to get a hiring interview.

\section{Experiment}

We wish to evaluate the answer that an applicant get with his characteristics and the answer he would have get with other characteristics. The most convenient way to collect such data is to perform an experiment. We construct a set of applications with similar characteristics except for the history in the labour market.

Correspondence studies are best suited to measure the effect of an individual characteristic on the chances of getting a job (Riach and Rich, 2002; Neumark, 2012). It consists in building fictitious applications that are practically identical apart from the trait whose effect we want to evaluate and then to send them simultaneously in response to the same job offers. One can then evaluate how the chances of success vary between the fictitious applicants. This method eliminates the unobservable heterogeneity of job applicants and the self-selection bias. Its main limitation is related to the necessarily limited size of the experiment. Evaluations from correspondence tests produce a one-time measurement for specific professions (Heckman, 1998). However, it reveals an information that no other data source can provide: the answers that were given by the recruiters to several competitors for the same job.

Choice of professions. We chose professions which satisfy two criteria: a tight labour market and a large number of offers. A tight labour market, defined as a large number of job offers per job seeker, was chosen both to have a high response rate and to obtain a lower bound estimate of discrimination (Baert et al. 2013). If discrimination occurs in a tight labour market, it should be worse in the professions sharing common characteristics. The second criterion, a large number of job offers, allows for reducing detection by reducing the share of the experimental applicants in the total applicants. This selection criteria have proven useful in a context of economic slowdown. 
Choice of candidates. For the two professions, the applicants are male, between 31 and 33 years old, with French sounding first and last names. They live inside Paris (13th, 14th and 15th districts), have a driving licence and a car. We have selected male applicants in order to avoid gender discrimination (Duguet and Petit, 2005), French sounding names in order to avoid ethnic discrimination (Duguet, Du Parquet, L'Horty and Petit, 2015), an address inside Paris in order to avoid address discrimination (Duguet, Gray, L'Horty, Du Parquet and Petit, 2017) and a driving licence for the same reason (Duguet, Du Parquet, L'Horty and Petit, 2017). The candidates have responded to the job adds between February and May 2015. From this basis, we define the five following profiles:

- LTC: Long term contracts profile. It is the benchmark situation, no discrimination is expected in this case. This candidate has 12 years of experience with four long term contracts. These contracts have had an increasing duration over time. The last position is held since 2011.

- PTC: Part time contracts profile. This profile is close to the previous one, with long term contracts only, but includes two periods of part time contract. The worker start with three years and a half on a full time job, then one year on a part time job, then five years and a half one full time job, and moved on a part time job over the last two years before the test period. Overall, it makes only three years with a part time job, but the two last may count more for the recruiter. Since the worker has no child, it could indicate either health problems, or the will to spend more time on leisure or on another business.

- STU: Short term unemployed profile. This profile is similar to the long term contract profile but includes a short unemployment period at the end. The unemployment period starts in October 2014. Since the test is made between February and may 2015, the unemployment duration is between 4 and 7 months.

- LTU: Long term unemployed profile. This profile is similar to the long term contract profile (LTC) but includes a period of unemployment starting in january 2014. The unemployment duration is between 13 and 17 months.

- STC: Short term contracts profile, on full time jobs. This profile is the most different from the baseline case. It includes 7 periods of employment because the contracts are shorter. The worker has started with two short term contracts, moved to a long term contract of 
5 years, and then to a series of four short term contracts. The last contract started in May 2014.

Given that these applications were sent simultaneously in response to the same job offers, the applications had to include elements of differentiation. These differences concern the resume presentations, i.e. font type, font size and page layout, all the while remaining standard in form. The applicants offer experience acquired in real companies; these firms differ, but are comparable in terms of their activities, size, market power, etc. The applicants' leisure activities are different as well, while also remaining very typical and impersonal (team sports, individual sports, cinema, reading, music, etc.). The short emails sent along with the resumes were also worded differently, while remaining standard in style. An address, cell phone number and email address were attributed to each applicant. These resumes were compiled based on the expertise of representatives from each of the vocational fields in question, people consulted for their opinions as to whether or not the applications appear realistic.

Another important point for avoiding detection is the number of candidates who reply on each job post in the real labour market. The more the better. The only reliable data that we could find was about executives. Since the jobs in our study are less qualified than these, we interpret the executives' number of applicants as lower bounds for our professions. According to APEC (2017), each job post for sales executives received on average 44 candidates in the first quarter of 2015 and 54 candidates in the second quarter. For accounting executives, the figures are respectively 57 and 52 for each offer. Overall, considering that these figures are lower bound, our experiment is likely to have avoided detection.

Responses to job offers. We carried out a simple job interview test by sending applications for the same job offer after the job was posted online, at short intervals by email from the email address of each applicant, or by regular mail . By this way, no applicant had to undergo the interview in person. Our outcomes are call-back rates. This method was chosen for two reasons. Firstly, interviews introduce bias on the part of recruiters related to the applicants' physical appearance and personality. These unavoidable biases are not perceptible by researchers and are impossible to control. We assume that since interviews generate a cost, the recruiter would invite for an interview only applicants who objectively have a chance to obtain the position. No photograph were added to written applications. Secondly, since the data collection process is less burdensome and is completed within a given time period, we were able to constitute a 
larger sample. Finally, in order to ensure that the formatting or content of a specific application would not systematically influence companies' choices of a particular applicant (in spite of the precautions taken when the applications were created), we interchanged the resume layouts and cover letters between the applicants.

Table 1: Data collection

\begin{tabular}{|c|c|c|c|c|c|c|}
\hline \multirow{2}{*}{$\begin{array}{l}\text { Profession } \\
\text { Contract }\end{array}$} & \multicolumn{3}{|c|}{ Sales assistant } & \multicolumn{3}{|c|}{ Accountant } \\
\hline & Full time & Part time & N.A. & Full time & Part time & N.A. \\
\hline Long term & 237 & 2 & 0 & 228 & 3 & 1 \\
\hline Short term & 57 & 1 & 0 & 57 & 1 & 0 \\
\hline N.A. & 2 & 0 & 1 & 4 & 1 & 5 \\
\hline Post used & \multicolumn{3}{|c|}{294} & \multicolumn{3}{|c|}{285} \\
\hline Observations & \multicolumn{3}{|c|}{1470} & \multicolumn{3}{|c|}{1425} \\
\hline \multicolumn{7}{|c|}{ Independence of the recruiter's answer with $:^{*}$} \\
\hline Sending order & \multicolumn{3}{|c|}{0.88} & \multicolumn{3}{|c|}{0.23} \\
\hline Paris district & \multicolumn{3}{|c|}{0.57} & \multicolumn{3}{|c|}{0.31} \\
\hline Overall success $^{\dagger}$ & \multicolumn{3}{|c|}{$34.2 \%$} & \multicolumn{3}{|c|}{$36.1 \%$} \\
\hline
\end{tabular}

In order to implement our estimation method we need both to know the contract term (short, long) and full time jobs. Short term contracts are defined by a duration strictly lower than 12 months. Long term contracts are defined as either undefined term contracts or contracts for 12 months and more. We keep full time jobs because they represent almost all the offers for accountants and sales assistants. Our method could be easily be adapted to part time jobs if there was enough observations. Table 1 summarizes the data available. Most of the posts include enough information for our discrimination analysis. We also report two important independence tests. The first test checks whether the answer of the recruiter depends on the sending order. The second test examines whether the answer depends on the address of the candidates. We find that the rotation of the CVs was efficient since the answers do not depend on the sending order. Similarly, the Paris districts were adequately chosen since the addresses of the candidates did not influence significantly the answers of the recruiters. The overall success rate is close to one third, which indicates a tight labour market in France. 


\section{Model}

We can summarize the success probabilities of the candidates by the following system. The letter $\mathrm{L}$ refers to the offers of long term contracts :

$$
\begin{aligned}
\operatorname{Pr}(\mathrm{LTC}, \mathrm{L}) & =\theta_{L}+u_{L, i} \\
\operatorname{Pr}(\mathrm{STU}, \mathrm{L}) & =\theta_{L}+\delta_{U}+u_{L, i} \\
\operatorname{Pr}(\mathrm{LTU}, \mathrm{L}) & =\theta_{L}+\delta_{U}+\delta_{L}+u_{L, i} \\
\operatorname{Pr}(\mathrm{PTC}, \mathrm{L}) & =\theta_{L}+\delta_{P}+u_{L, i} \\
\operatorname{Pr}(\mathrm{STC}, \mathrm{L}) & =\theta_{L}+\delta_{S}+u_{L, i} \\
\mathrm{E}\left(u_{L, i}\right) & =0
\end{aligned}
$$

The candidate with a history of long term contracts, the (LTC,L) case, should experience no discrimination when he replies to a long term contract offer since he has no characteristic susceptible to attract it. His average probability of success is $\theta_{L}$, a measure of labour market tightness for long term contracts. To this component we add $u_{L, i}$, an unobserved heterogeneity term at the job post level. This heterogeneity term may be correlated with the characteristics of the candidates, so that we have to eliminate it by differencing in order to get unbiased estimates. We set $\mathrm{E}\left(u_{L, i}\right)=0$ without loss of generality because the model includes a constant term $\theta_{L}$.

The candidate with one year of unemployment (STU,L) faces a specific effect $\delta_{U}$. Its sign is undetermined: on the one hand, unemployed workers are immediately available in a tight labour market so that firms could prefer short term unemployed workers to candidates with a long term contract because the latter must respect a notice period between one and three months $\left(\delta_{U}>0\right)$ and, on the other hand, unemployed workers could experience a statistical discrimination on their expected productivity $\left(\delta_{U}<0\right)$. The argument may be stronger for the long term unemployed (LTU) and they could suffer from a specific stigma $\delta_{L}$. The total effect for the long term unemployed workers is $\delta_{U}+\delta_{L}$, the sum of the unemployment and stigma effects.

There remains two profiles that we wish to test: long term part time contracts (PTC,L) and the short term contracts (STC,L). $\delta_{P}$ is the potential statistical discrimination against the workers with a long history of part time contracts. According to Pak (2013), the male workers who have decided to work part time dit it for the following reasons: the inability to find a full time contract (37\%), another professional or training activity (18\%), health problems (11\%), the will to have free time $(11 \%)$ and helping family members $(7 \%)$. Since there is almost no part time 
job offer in the two professions that we test, we can disregard the inability to find a full time job. The four other reasons have one point in common: they imply a lower work involvement in the job than full-time workers. The recruiter may therefore have doubts about the ability of the candidate to shift easily from a part-time to a full-time job or to accept overtime, and rank the candidate with a part-time history below the other workers and we should find $\delta_{P}<0$. Last, the workers with a long history of short term contracts (STC,L) could be discriminated against because they have not successfully found a stable job by the age of 30 , and this may generate doubts about their professional skills. In fact the issue is a bit more complicated since, in France, short terms contract benefit from a specific legal premium (the "precariousness bonus") equal to $10 \%$ of the total wage of the contract period, so that workers could prefer short term contracts because they want to earn more. The workers with these profile would trade their job stability for a $10 \%$ wage bonus. We denote the reaction of the recruiter as $\delta_{S}$.

We go further by considering the job posts for short term contracts (denoted S). Here, we will consider that every candidate with a former long term contract could suffer from a "bad transition" statistical discrimination. On the one hand these workers lose the security of their previous contract and the recruiter may wonder why the candidate accepts this situation but, on the other hand, it may also indicate the will to get the $10 \%$ wage bonus at the end of the contract period. We denote $\delta_{R}$ the effect associated with a contract term reduction. The five probabilities become :

$$
\begin{aligned}
\operatorname{Pr}(\mathrm{LTC}, \mathrm{S}) & =\theta_{S}+\delta_{R}+u_{S, i} \\
\operatorname{Pr}(\mathrm{STU}, \mathrm{S}) & =\theta_{S}+\delta_{U}+u_{S, i} \\
\operatorname{Pr}(\mathrm{LTU}, \mathrm{S}) & =\theta_{S}+\delta_{U}+\delta_{L}+u_{S, i} \\
\operatorname{Pr}(\mathrm{PTC}, \mathrm{S}) & =\theta_{S}+\delta_{R}+\delta_{P}+u_{S, i} \\
\operatorname{Pr}(\mathrm{STC}, \mathrm{S}) & =\theta_{S}+u_{S, i} \\
\mathrm{E}\left(u_{S, i}\right) & =0
\end{aligned}
$$

where $\theta_{S}$ is the tightness in the labour market for short term contracts and $u_{S, i}$ the post level unobserved heterogeneity on the probabilities of success for the short term contracts. One difference appears with the previous case for the short term contracts: it is not a source of discrimination for short run contracts, since it involves a continuity of the labour market status.

The aim of this application is to estimate the interest parameters $\left(\theta_{L}, \delta_{U}, \delta_{L}, \delta_{P}, \delta_{S}, \theta_{S}, \delta_{R}\right)$ from the raw success proportions of the candidate. We explain how in the next section. 


\section{Method}

The method both solves an overidenfication issue and provides a minimum variance estimator. The problem was originally created by the need to separate the posts on short and long run contracts. It had for consequence to provide two estimators for the parameters $\delta_{U}, \delta_{L}, \delta_{P}$. We fix this problem by first testing the equality of the different estimators and, since the test is conclusive in our application, we provide the minimum variance estimates of the discrimination parameters.

This method may be of a more general interest. Indeed, the OLS disturbances of the linear probability models commonly used in the literature are heteroskedastic. Correcting the standard errors allows for a correct inference, but OLS is still not the best estimation method in this case. Using a Probit model estimated by maximum likelihood may provide an asymptotically optimal inference under the normality of the disturbances, but this assumption cannot be tested. With our method, optimality is explicitly addressed, and the normality properties of the estimates results from the law of large numbers, not from an assumption.

The first thing to do is to eliminate unobserved heterogeneity since its presence can bias the estimates. All the $\delta$ parameters will be estimated from differences and are, therefore, corrected for unobserved heterogeneity. Only the $\theta$ estimates are obtained from the levels and are influenced by the unobserved heterogeneity, but they do not measure discrimination. In what follow, we focus on the estimation of the discrimination components.

For the long term contracts, the elimination of the unobserved heterogeneity is done by differencing from the baseline case (LTC,L), except for long term unemployment, where differencing with the short term unemployment case is more relevant. We take the following differences, in order to identify the discrimination parameters.

$$
\begin{aligned}
& \mathrm{D}(\mathrm{STU}, \mathrm{L})=\operatorname{Pr}(\mathrm{STU}, \mathrm{L})-\operatorname{Pr}(\mathrm{LTC}, \mathrm{L})=\delta_{U} \\
& \mathrm{D}(\mathrm{LTU}, \mathrm{L})=\operatorname{Pr}(\mathrm{LTU}, \mathrm{L})-\operatorname{Pr}(\mathrm{STU}, \mathrm{L})=\delta_{L} \\
& \mathrm{D}(\mathrm{PTC}, \mathrm{L})=\operatorname{Pr}(\mathrm{PTC}, \mathrm{L})-\operatorname{Pr}(\mathrm{LTC}, \mathrm{L})=\delta_{P} \\
& \mathrm{D}(\mathrm{STC}, \mathrm{L})=\operatorname{Pr}(\mathrm{STC}, \mathrm{L})-\operatorname{Pr}(\mathrm{LTC}, \mathrm{L})=\delta_{S}
\end{aligned}
$$

For the short term contracts, we eliminate the heterogeneity terms by differencing from the most relevant case in the same post: 


$$
\begin{aligned}
\mathrm{D}(\mathrm{LTC}, \mathrm{S}) & =\operatorname{Pr}(\mathrm{LTC}, \mathrm{S})-\operatorname{Pr}(\mathrm{STC}, \mathrm{S})=\delta_{R} \\
\mathrm{D}(\mathrm{STU}, \mathrm{S}) & =\operatorname{Pr}(\mathrm{STU}, \mathrm{S})-\operatorname{Pr}(\mathrm{STC}, \mathrm{S})=\delta_{U} \\
\mathrm{D}(\mathrm{LTU}, \mathrm{S}) & =\operatorname{Pr}(\mathrm{LTU}, \mathrm{S})-\operatorname{Pr}(\mathrm{STU}, \mathrm{S})=\delta_{L} \\
\mathrm{D}(\mathrm{PTC}, \mathrm{S}) & =\operatorname{Pr}(\mathrm{PTC}, \mathrm{S})-\operatorname{Pr}(\mathrm{LTC}, \mathrm{S})=\delta_{P}
\end{aligned}
$$

Overall, the 8 probability differences allow for the identification of the five discrimination parameters $\left(\delta_{U}, \delta_{L}, \delta_{P}, \delta_{S}, \delta_{R}\right)$, so that we have 3 degrees of freedom. They come from the fact that there are two different ways to compute the tree parameters $\left(\delta_{U}, \delta_{L}, \delta_{P}\right)$. The model is overidentified, and we will have to test that these additional constraints are satisfied.

The previous identification constraints provide our estimating equations. The theoretical relationships can be written under a more convenient matrix form, by stacking all the constraints together :

$$
\underbrace{\left(\begin{array}{l}
\mathrm{D}(\mathrm{STU}, \mathrm{L}) \\
\mathrm{D}(\mathrm{LTU}, \mathrm{L}) \\
\mathrm{D}(\mathrm{PTC}, \mathrm{L}) \\
\mathrm{D}(\mathrm{STL}, \mathrm{L}) \\
\mathrm{D}(\mathrm{LTC}, \mathrm{S}) \\
\mathrm{D}(\mathrm{STU}, \mathrm{S}) \\
\mathrm{D}(\mathrm{LTU}, \mathrm{S}) \\
\mathrm{D}(\mathrm{PTC}, \mathrm{S})
\end{array}\right)}_{\pi}=\underbrace{\left(\begin{array}{lllll}
1 & 0 & 0 & 0 & 0 \\
0 & 1 & 0 & 0 & 0 \\
0 & 0 & 1 & 0 & 0 \\
0 & 0 & 0 & 1 & 0 \\
1 & 0 & 0 & 0 & 0 \\
0 & 1 & 0 & 0 & 0 \\
0 & 0 & 1 & 0 & 0 \\
0 & 0 & 0 & 0 & 1
\end{array}\right)}_{A} \underbrace{\left(\begin{array}{c}
\delta_{U} \\
\delta_{L} \\
\delta_{P} \\
\delta_{S} \\
\delta_{R}
\end{array}\right)}_{\beta}
$$

or

$$
\pi=A \beta
$$

where $\pi$ is the vector of the theoretical differenced probabilities (i.e. the auxiliary parameters in the ALS terminology), $A$ is the identification matrix and $\beta$ regroups the theoretical discrimination coefficients (i.e. the parameters of interest in the ALS terminology). We easily obtain a CAN estimator of $\pi$ from the empirical probabilities 1 It is estimated from the raw success percentages of the candidates. When we replace the theoretical probabilities by they empirical counterpart we get an error term $\omega$ defined by: $\hat{\pi}=\pi+\omega$, with $\operatorname{Plim} \sqrt{N} \omega=0$, where $N$ is the sample size. Reporting in the previous equation, we get :

$$
\hat{\pi}=A \beta+\omega,
$$

\footnotetext{
${ }^{1}$ CAN: Consistent and Asymptotically Normal.
} 
since $\hat{\pi}$ and $A$ are observable we can estimate this relationship by FGLS in one stage only $\left.\right|^{2}$ This is the Asymptotic Least Squares method $\hat{\Omega}^{3}$ Let $\hat{\Omega}$ be the estimated covariance matrix of $\hat{\pi}$, we get the optimal estimator of the discrimination coefficients:

$$
\hat{\beta}=\left(A^{\prime} \hat{\Omega}^{-1} A\right)^{-1} A^{\prime} \hat{\Omega}^{-1} \hat{\pi}
$$

with estimated covariance matrix:

$$
\hat{\mathrm{V}}(\hat{\beta})=\left(A^{\prime} \hat{\Omega}^{-1} A\right)^{-1} .
$$

The overidentification statistic is simply a norm computed on the estimated error term of our relationship, $\hat{\omega}=\hat{\pi}-A \hat{\beta}$, we get :

$$
S=\hat{\omega}^{\prime} \hat{\Omega}^{-1} \hat{\omega}
$$

under the null hypothesis $(\omega=0)$, it is asymptotically $\chi^{2}(3)$ distributed.

\section{Results}

The raw callback rates are reported in appendix. The ALS results are presented in table 2 The tightness on sales assistant jobs is the same for short term and long term contracts $\left(\theta_{L}=\theta_{S}\right)$. The standard (LTC) candidate has a success rate around $20 \%$. It receives, on average, one positive answer for five applications. We find that two types of candidates suffer from statistical discrimination. The part time contract candidate has much less chances to be recruited (-7.3 points). This may reflect the beliefs of the employers about the reason why these male candidates have a part time jobs. Considering the reasons given by Pak (2013) we may explain this results by the motivations of part time jobs for men: having another job or being in training, the will to have free time, health problems and the need to help family members. This activities could send bad productivity or involvement signals and motivate a rejection since other candidates are available. More precisely, if health is the cause of the previous part time job, one cannot exclude a probability of failure. Baert et al. (2016) provided evidence of discrimination against men with one year of depression. More generally, statistical discrimination, would

\footnotetext{
${ }^{2}$ FGLS: Feasible Generalized Least Squares.

${ }^{3}$ It was originally developed by Gouriéroux, Monfort and Trognon (1982, 1985) and Chamberlain (1982, 1984).
} 
cause the rejection of the candidate. Last, helping family members can imply to be less available for a full time job. The recruiter may anticipate a potentially lower involvement in the job and prefer another candidate.

The second significant effect affects workers with a previous history of short term contracts. Since the contracts in this profession are mostly long term contracts, $76 \%$ of the posts, this history could indicate either a bad potential productivity or a will to get the $10 \%$ precariousness bonus. Here the result may be explained by the age of the candidate, around 30, and by firms' common practice of using the short term contracts as trial periods. At this age, the hypothesis of a failure to find a stable job may be favoured by the recruiters. The recruiters may expect that the workers with a long history of short term contracts have failed to convince their previous employers to recruit them on a long term contract. We could not use this argument for younger workers because short term contracts are common at the beginning of the career, but here the candidates have been in the labour market over the last twelve years and the failure hypothesis may be favoured by the a significant part of the recruiters. Overall, we find that it results in a penalty of 4.2 points. 
Table 2: Discrimination components estimates - Asymptotic Least Squares

\begin{tabular}{lccccccc}
\hline \hline Profession & \multicolumn{9}{c}{ Sales assistant } & \multicolumn{3}{c}{ Accountant } \\
\hline Backward elimination & $(1)$ & $(2)$ & $(3)$ & $(4)$ & $(1)$ & $(2)$ & $(3)$ \\
\hline Levels & & & & & & & \\
$\theta_{L}$ & $0.190^{*}$ & $0.190^{*}$ & $0.190^{*}$ & $0.201^{*}$ & $0.218^{*}$ & $0.200^{*}$ & $0.200^{*}$ \\
Std. Dev & 0.025 & 0.025 & 0.025 & 0.022 & 0.027 & 0.023 & 0.023 \\
$\theta_{S}$ & $0.211^{*}$ & $0.219^{*}$ & $0.219^{*}$ & $0.224^{*}$ & $0.105^{*}$ & $0.105^{*}$ & $0.158^{*}$ \\
Std. Dev & 0.054 & 0.051 & 0.051 & 0.047 & 0.041 & 0.041 & 0.041 \\
Differences & & & & & & & \\
$\delta_{U}$ & 0.024 & 0.023 & 0.016 & & $0.065^{*}$ & $0.074^{*}$ & $0.072^{*}$ \\
Std. Dev & 0.023 & 0.023 & 0.020 & & 0.022 & 0.020 & 0.020 \\
$\delta_{L}$ & -0.015 & -0.015 & & & $-0.071^{*}$ & $-0.075^{*}$ & $-0.080^{*}$ \\
Std. Dev & 0.020 & 0.020 & & & 0.024 & 0.024 & 0.024 \\
$\delta_{P}$ & $-0.062^{*}$ & $-0.063^{*}$ & $-0.063^{*}$ & $-0.073^{*}$ & $-0.044^{*}$ & $-0.037^{\dagger}$ & $-0.045^{*}$ \\
Std. Dev & 0.020 & 0.020 & 0.020 & 0.019 & 0.021 & 0.019 & 0.018 \\
$\delta_{S}$ & -0.032 & -0.033 & -0.032 & $-0.042^{*}$ & -0.019 & & \\
Std. Dev & 0.024 & 0.024 & 0.024 & 0.021 & 0.023 & & \\
$\delta_{R}$ & 0.012 & & & & 0.042 & 0.048 & \\
Std. Dev & 0.035 & & & & 0.039 & 0.038 & \\
\hline Overidentification & 0.634 & 0.684 & 0.576 & 0.270 & 0.081 & 0.154 & 0.604 \\
p-value & & & & & & & \\
\hline Long term posts & 237 & & & & 228 & & \\
Short term posts & 57 & & & & 57 & & \\
Total posts & 294 & & & & 1425 & & \\
Observations & 1470 & & & & & & \\
\hline \hline
\end{tabular}

*: significant at $5 \% . \dagger$ : significant at $10 \%$. 
We turn to the accountant profession. The success for the reference candidate (LTC,L) is higher for long term contracts, but not significantly at the $5 \%$ level. The main differences between the candidates come from the unemployment status and the term of the labour contract.

The workers with less than one year of unemployment are the most favoured candidate. They get an advantage of 7.2 points compared to the benchmark candidate. The reason may simply be that, on the one hand, they are immediately available and, on the other hand, their career interruption is too short to generate adverse beliefs about their productivity. We get a different result for the workers who have been unemployed for more than two years. They lose all the availability advantage of the short term unemployed. Compared to them, their hiring probability diminishes by 8 points. However, they do not lose all their capacity to get a hiring interview because these two effects offset each other. The total effect is close to zero and this means that the long term unemployed have the same success probability than the workers with a long term contract. But this very result shows an interesting point: the firms give the same chances to the long term contract and the long term unemployed while the former workers will not be immediately available and the latter workers are immediately available $4_{4}^{4}$ This may reflect a better opinion about the on-the-job candidates.

Last, we also find a negative effect for part-time workers, at 4.5 points. This results is similar to the one obtained on sales assistants jobs, and should also explain it by the anticipation of the employers about the future health and involvement of the candidate.

\section{Conclusion}

Labour market history has an impact on the current probability to be invited to a hiring interview. Workers with a profile of part time contracts have a significantly lower probability to be invited in both accountant and sales assistant jobs. this effect can be reasonably attributed to signalling. The workers who have chosen this type of job could be reputed to be less able or less willing to get involved in a full time job. For the sales assistant jobs, we find that the success probability is also smaller with a history of short term contracts. We also interpret it as a signalling effect. The results is different for accountants. Here, the probability of success decreases with the time spent in unemployment. While short term unemployed are favoured, due to their immediate availability in a tight labour market, the long term unemployed lose this

\footnotetext{
${ }^{4} \mathrm{~A}$ worker can leave after a compulsory legal notice of 1 to 3 months
} 
advantage. In this case, an anticipated depreciation of human capital could have motivated the recruiters.

\section{References}

[1] APEC (2017). De l'offre au recrutement, édition 2016. Les études de l'emploi du cadre, No. 2017-1, $62 \mathrm{p}$.

[2] Arceo-Gomez, E. O., Campos-Vazquez, R. M. (2014). Race and Marriage in the Labor Market: A Discrimination Correspondence Study in a Developing Country. American Economic Review, 104(5): 376-80.

[3] Arrow, K. J., (1973). The Theory of Discrimination, in O. Ashenfelter and A. Rees (eds.), Discrimination in Labor Markets, Princeton, NJ: Princeton University Press.

[4] Baert, S., B. Cockx, N. Geyle and C. Vandamme (2013). Do employers discriminate less if vacancies are difficult to fill? Evidence from a field experiment. IZA discussion paper No 7145 .

[5] Baert, S., Verhaest, D. (2014). Unemployment or Overeducation: Which is a Worse Signal to Employers? IZA, DP No. 8312.

[6] Baert, S., De Visschere, S., Schoors, K., Vandenberghe, D., Omey, E. (2016). First depressed, then discriminated against? Social Science and Medicine, 170, 247-254.

[7] Becker, G. (1994). Human Capital: A theoretical and empirical analysis with special reference to Education. The University of Chicago Press.

[8] Benoteau, I. (2015). Quels effets du recrutement en contrat aidé sur la trajectoire professionnelle? Une évaluation à partir du Panel 2008. Economie et Statistique, No 477, 85-129.

[9] Bertrand, M. (2013). New Perspectives on Gender. Handbook of Labor Economics, Volume 4b. Elsevier.

[10] Birkelund, G. E., Heggebø K., Rogstad, J. (2017). Additive or Multiplicative Disadvantage? The Scarring Effects of Unemployment for Ethnic Minorities. European Sociological Review, 33(1), 17-29.

[11] Blanchard, O., and Summers, L., (1986), Hysteresis and the European Unemployment Problem, p. 15-90 in , NBER Macroeconomics Annual 1986, Volume 1, National Bureau of Economic Research, Inc.

[12] Cahuc, P., Carcillo, S., Minea, A. (2017). The Difficult School-To-Work Transition of High School Dropouts: Evidence from a Field Experiment. IZA, DP No. 10842.

[13] Chamberlain, G. (1982). Multivariate regression models for panel data, Journal of Econometrics, 18, 5-46.

[14] Chamberlain, G. (1984). Panel data. in Z. Griliches, and M. D. Intriligator (eds), Handbook of Econometrics, Vol. II, Elsevier, Amsterdam, 1247-1318. 
[15] Duguet, E., Du Parquet L, L'Horty Y. and Petit P. (2015). New Evidence of Ethnic and Gender discriminations in the French Labor Market using experimental data: A ranking extension of responses from correspondence tests. Annals of Economics and Statistics, No 117-118, 21-39.

[16] Duguet, E., Du Parquet L., L'Horty Y., Petit P., (2017). Counterproductive hiring discrimination against women: evidence from a French correspondence test. International Journal of Manpower, forthcoming.

[17] Duguet, E., D. Gray, Y. L'Horty, L. Du Parquet and P. Petit (2017). Labor market effects of urban riots: an experimental assessment. University of Ottawa, Department of Economics, Working Paper \#1711E.

[18] Duguet, E., Petit, P. (2005). Hiring discrimination in the French financial sector: an econometric analysis on field experiment data. Annals of Economics and Statistics, 78, 79-102.

[19] Eriksson, S., Rooth, D. O. (2014). Do employers use unemployment as a sorting criterion when hiring? Evidence from a field experiment. The American Economic Review, 104(3), 1014-1039.

[20] Fontaine, M., Rochut, J. (2014). Reduced activity of job seekers: which impact on return to employment and its quality? Revue Economique, 65(4), 621-644.

[21] Fremigacci, F., Terracol, A. (2013). Subsidized temporary jobs: lock-in and stepping stone effects. Applied Economics, 45(33), 4719-4732.

[22] Givord, P. (2005). Formes particulières d'emploi et insertion des jeunes. Economie et Statistique, 388(1), 129-143.

[23] Gouriéroux, C., A. Monfort, and A. Trognon (1982). Nonlinear asymptotic least squares. INSEE, Working paper \#8207.

[24] Gouriéroux, C., A. Monfort, and A. Trognon (1985). Moindres carrés asymptotiques. Annales de l'INSEE, 58, 91-122.

[25] Heckman, J. J. (1998). Detecting Discrimination, Journal of Economic Perspectives, 12 (2), 101-116.

[26] Kroft, K., Lange, F., Notowidigdo, M. J., Katz, L. F. (2016). Long-Term Unemployment and the Great Recession: The Role of Composition, Duration Dependence, and Nonparticipation. Journal of Labor Economics, 34(S1).

[27] Kroft, K., Lange, F, Notowidigdo, M. J. (2013). Duration Dependence and Labor Market Conditions: Evidence from a Field Experiment. The Quarterly Journal of Economics, 128(3), 1123-1167.

[28] Krueger, A.B., J. Cramer and D. Cho (2014). Are the Long-Term Unemployed on the Margins of the Labor Market? Brookings Papers on Economic Activity, Spring 2014 Conference.

[29] Neumark, D. (2012). Detecting discrimination in audit and correspondence studies. Journal of Human Resources, 47(4), 1128-1157. 
[30] Oberholzer-Gee, F. (2008). Nonemployment stigma as rational herding: A field experiment. Journal of Economic Behavior \& Organization, 65(1), 30-40.

[31] Pak, M. (2013). Le temps partiel en 2011. DARES Analyses, No 2013-5, January.

[32] Riach, P. A., Rich, J. (2002). Field experiments of discrimination in the market place. The Economic Journal, 112(483), 480-518.

[33] Spence, M. (1973). Job Market Signaling. Quarterly Journal of Economics. 87 (3): 355-374.

[34] Van Belle, E., Caers, R., De Couck, M., Di Stasio, V., Baert S. (2017). Why Is Unemployment Duration a Sorting Criterion in Hiring? IZA, DP No. 10876. 


\section{A Additional Statistics}

Table 3: Callback rates

\begin{tabular}{lccccc}
\hline \hline Profession & & \multicolumn{2}{c}{ Sales assistant } & \multicolumn{2}{c}{ Accountant } \\
\hline Path & Shortcut & Prob & Std. Dev & Prob. & Std. Dev \\
\hline Long term contracts & (LTC,L) & 0.190 & 0.025 & 0.218 & 0.027 \\
Short term unemployed & (STU,L) & 0.211 & 0.027 & 0.265 & 0.029 \\
Long term unemployed & (LTU,L) & 0.203 & 0.026 & 0.176 & 0.025 \\
Part time contracts & (PTC,L) & 0.118 & 0.021 & 0.151 & 0.023 \\
Short term contracts & (STC,L) & 0.156 & 0.024 & 0.181 & 0.025 \\
& & \multicolumn{3}{c}{ Short term contract offers } \\
Long term contracts & (LTC,S) & 0.228 & 0.056 & 0.211 & 0.054 \\
Short term unemployed & (STU,S) & 0.246 & 0.057 & 0.281 & 0.060 \\
Long term unemployed & (LTU,S) & 0.211 & 0.054 & 0.193 & 0.052 \\
Part time contracts & (PTC,S) & 0.193 & 0.052 & 0.123 & 0.043 \\
Short term contracts & (STC,S) & 0.211 & 0.054 & 0.105 & 0.041 \\
\hline \hline
\end{tabular}

*: significant at $5 \%$.

\section{B Constrained estimation}

When a parameter is not significant, it means that candidates from different groups have the same success probability. Therefore we should regroup them and estimate a global probability in order to increase the efficiency of the estimation. Interestingly, if we regroup two sets of candidates, we double the number of observations and this diminishes the standard errors of our estimates. The backward selection mechanism in our study is therefore very different from the standard regression case. This appendix gives a full account of the estimation in the case of sales assistants.

Regrouping candidates is equivalent to take the average probability because we send exactly the same number of people in each profile. Consider two groups of sample size $N$ with a success dummy variable $d_{i}$ ( 1 if success, 0 otherwise), $i \in G_{1}$ for group 1 and $i \in G_{2}$ for group 2, with respective success probabilities $\hat{p}_{1}=N^{-1} \sum_{i \in G_{1}} d_{i}$ and $\hat{p}_{2}=N^{-1} \sum_{i \in G_{2}} d_{i}$, the global success probability is equal to :

$$
\hat{p}=\frac{1}{2 N} \sum_{i \in G_{1} \cup G_{2}} d_{i}=\frac{N}{2 N}\left(\frac{1}{N} \sum_{i \in G_{1}} d_{i}+\frac{1}{N} \sum_{i \in G_{2}} d_{i}\right)=\frac{1}{2}\left(\hat{p}_{1}+\hat{p}_{2}\right)
$$


and the argument extends to any number of groups. One simply has to take the average of the probabilities. When we estimate the model for sales assistants, we first find $\delta_{R}=0$. Replacing $\delta_{R}$ in the identification constraints modifies the equations of the short term contracts only. We get that $\operatorname{Pr}(\mathrm{LTC}, \mathrm{S})=\operatorname{Pr}(\mathrm{STC}, \mathrm{S})$, the success is the same on short term contracts for the candidates who already have a long term or a short term contract. Therefore, we take the average of these probabilities and use the following new set of identification constraints :

$$
\begin{aligned}
\frac{1}{2} \operatorname{Pr}(\mathrm{LTC}, \mathrm{S})+\frac{1}{2} \operatorname{Pr}(\mathrm{STC}, \mathrm{S}) & =\theta_{S}+u_{S, i} \\
\operatorname{Pr}(\mathrm{STU}, \mathrm{S}) & =\theta_{S}+\delta_{U}+u_{S, i} \\
\operatorname{Pr}(\mathrm{LTU}, \mathrm{S}) & =\theta_{S}+\delta_{U}+\delta_{L}+u_{S, i} \\
\operatorname{Pr}(\mathrm{PTC}, \mathrm{S}) & =\theta_{S}+\delta_{P}+u_{S, i}
\end{aligned}
$$

estimation then proceeds by differencing in order to eliminate the unobserved heterogeneity term $u_{S, i}$ and applying ALS to the differences. We find that $\delta_{L}=0$. This time, it has consequences for the two blocks of the identification constraints (long term and short term). For the long term block, the two types of unemployed workers now share the same success probability $(\operatorname{Pr}(\mathrm{STU}, \mathrm{L})=\operatorname{Pr}(\mathrm{LTU}, \mathrm{L})$ so that we will use their average value. We get :

$$
\begin{aligned}
\operatorname{Pr}(\mathrm{LTC}, \mathrm{L}) & =\theta_{L}+u_{L, i} \\
\frac{1}{2} \operatorname{Pr}(\mathrm{STU}, \mathrm{L})+\frac{1}{2} \operatorname{Pr}(\mathrm{LTU}, \mathrm{L}) & =\theta_{L}+\delta_{U}+u_{L, i} \\
\operatorname{Pr}(\mathrm{PTC}, \mathrm{L}) & =\theta_{L}+\delta_{P}+u_{L, i} \\
\operatorname{Pr}(\mathrm{STC}, \mathrm{L}) & =\theta_{L}+\delta_{S}+u_{L, i}
\end{aligned}
$$

for the short term contracts, it will add one average to the already existing one :

$$
\begin{aligned}
\frac{1}{2} \operatorname{Pr}(\mathrm{LTC}, \mathrm{S})+\frac{1}{2} \operatorname{Pr}(\mathrm{STC}, \mathrm{S}) & =\theta_{S}+u_{S, i} \\
\frac{1}{2} \operatorname{Pr}(\mathrm{STU}, \mathrm{S})+\frac{1}{2} \operatorname{Pr}(\mathrm{LTU}, \mathrm{S}) & =\theta_{S}+\delta_{U}+u_{S, i} \\
\operatorname{Pr}(\mathrm{PTC}, \mathrm{S}) & =\theta_{S}+\delta_{P}+u_{S, i}
\end{aligned}
$$

estimation now proceeds by first differencing separately inside each block, because the heterogeneity terms $u_{L, i}$ and $u_{S, i}$ are different in the two blocks, and then applying ALS to the 
differences. We find $\delta_{U}=0$. The two blocks are strongly modified by this result. For the long term block, we have $\operatorname{Pr}(\mathrm{LTC}, \mathrm{L})=\operatorname{Pr}(\mathrm{STU}, \mathrm{L})=\operatorname{Pr}(\mathrm{LTU}, \mathrm{L})$ and for the short term block, we have $\operatorname{Pr}(\mathrm{LTC}, \mathrm{S})=\operatorname{Pr}(\mathrm{STU}, \mathrm{S})=\operatorname{Pr}(\mathrm{LTU}, \mathrm{S})=\operatorname{Pr}(\mathrm{STC}, \mathrm{S})$. Averaging the relevant probabilities, we get the following identification constraints for the long term block:

$$
\begin{aligned}
\frac{1}{3} \operatorname{Pr}(\mathrm{LTC}, \mathrm{L})+\frac{1}{3} \operatorname{Pr}(\mathrm{STU}, \mathrm{L})+\frac{1}{3} \operatorname{Pr}(\mathrm{LTU}, \mathrm{L}) & =\theta_{L}+u_{L, i} \\
\operatorname{Pr}(\mathrm{PTC}, \mathrm{L}) & =\theta_{L}+\delta_{P}+u_{L, i} \\
\operatorname{Pr}(\mathrm{STC}, \mathrm{L}) & =\theta_{L}+\delta_{S}+u_{L, i}
\end{aligned}
$$

and the following constraints for the short term block:

$$
\begin{aligned}
\frac{1}{4} \operatorname{Pr}(\mathrm{LTC}, \mathrm{S})+\frac{1}{4} \operatorname{Pr}(\mathrm{STU}, \mathrm{S})+\frac{1}{4} \operatorname{Pr}(\mathrm{LTU}, \mathrm{S})+\frac{1}{4} \operatorname{Pr}(\mathrm{STC}, \mathrm{S}) & =\theta_{S}+u_{S, i} \\
\operatorname{Pr}(\mathrm{PTC}, \mathrm{S}) & =\theta_{S}+\delta_{P}+u_{S, i}
\end{aligned}
$$

estimations proceeds by two separate block differencing followed by ALS. All the remaining coefficients are significant at the $5 \%$ level. 
18-2. Occupational mobility and vocational training over the life cycle Anthony Terriau

18-1. Retired, at last? The short-term impact of retirement on health status in France Thomas Barnay, Eric Defebvre 
17-11. Hiring discrimination against women: distinguishing taste based discrimination from statistical discrimination

Emmanuel Duguet, Loïc du Parquet, Pascale Petit

17-10. Pension reforms, older workers' employment and the role of job separation and finding rates in France

Sarah Le Duigou, Pierre-Jean Messe

17-9. Healthier when retiring earlier? Evidence from France

Pierre-Jean Messe, François-Charles Wolff

17-8. Revisting Hopenhayn and Nicolini's optimal unemployment insurance with job search monitoring and sanctions

Sebastien Menard, Solenne Tanguy

17-7. Ethnic Gaps in Educational Attainment and Labor-Market Outcomes: Evidence from France

Gabin Langevin, David Masclet, Fabien Moizeau, Emmanuel Peterle

17-6. Identifying preference-based discrimination in rental market: a field experiment in Paris

Mathieu Bunel, Yannick L’Horty, Loïc du Parquet, Pascale Petit

17-5. Chosen or Imposed? The location strategies of households

Emilie Arnoult, Florent Sari

17-4. Optimal income taxation with composition effects

Laurence Jacquet, Etienne Lehmann

17-3. Labor Market Effects of Urban Riots: an experimental assessment

Emmanuel Duguet, David Gray, Yannick L'Horty, Loic du Parquet, Pascale Petit

17-2. Does practicing literacy skills improve academic performance in first-year university students? Results from a randomized experiment

Estelle Bellity, Fabrices Gilles, Yannick L'Horty

17-1. Raising the take-up of social assistance benefits through a simple mailing: evidence from a French field experiment

Sylvain Chareyron, David Gray, Yannick L'Horty 
16-8. Endogenous wage rigidities, human capital accumulation and growth Ahmed Tritah

16-7. Harder, better, faster...yet stronger? Working conditions and self-declaration of chronic diseases

Eric Defebvre

16-6. The influence of mental health on job retention

Thomas Barnay, Eric Defebvre

16-5. The effects of breast cancer on individual labour market outcomes: an evaluation from an administrative panel

Thomas Barnay, Mohamed Ali Ben Halima, Emmanuel Duguet, Christine Le Clainche, Camille Regaert

16-4. Expectations, Loss Aversion, and Retirement Decisions in the Context of the 2009 Crisis in Europe

Nicolas Sirven, Thomas Barnay

16-3. How do product and labor market regulations affect aggregate employment, inequalities and job polarization? A general equilibrium approach

Julien Albertini, Jean-Olivier Hairault, François Langot, Thepthida Sopraseuth

16-2. Acces to employment with age and gender: results of a controlled experiment Laetitia Challe, Florent Fremigacci, François Langot, Yannick L'Horty, Loïc Du Parquet, Pascale Petit

16-1. An evaluation of the 1987 French Disabled Workers Act: Better paying than hiring

Thomas Barnay, Emmanuel Duguet, Christine Le Clainche, Yann Videau 
15-10. Optimal Income Taxation with Unemployment and Wage Responses: A Sufficient Statistics Approach

Kory Kroft, Kavan Kucko, Etienne Lehmann, Johannes Schmieder

15-9. Search frictions and (in) efficient vocational training over the life-cycle Arnaud Chéron, Anthony Terriau

15-8. Absenteeism and productivity: the experience rating applied to employer contributions to health insurance

Sébastien Ménard, Coralia Quintero Rojas

15-7. Take up of social assistance benefits: the case of homeless Sylvain Chareyron

15-6. Spatial mismatch through local public employment agencies. Answers from a French quasi-experiment

Mathieu Bunel, Elisabeth Tovar

15-5. Transmission of vocational skills at the end of career: horizon effect and technological or organisational change

Nathalie Greenan, Pierre-Jean Messe

15-4. Protecting biodiversity by developing bio-jobs: A multi-branch analysis with an application on French data

Jean De Beir, Céline Emond, Yannick L'Horty, Laetitia Tuffery

15-3. Profit-Sharing and Wages: An Empirical Analysis Using French Data Between 2000 and 2007

Noélie Delahaie, Richard Duhautois

15_2. A meta-regression analysis on intergenerational transmission of education: publication bias and genuine empirical effect

Nicolas Fleury, Fabrice Gilles

15_1. Why are there so many long-term unemployed in Paris?

Yannick L'Horty, Florent Sari 
14-14. Hiring discrimination based on national origin and the competition between employed and unemployed job seekers

Guillaume Pierné

14-13. Discrimination in Hiring: The curse of motorcycle women

Loïc Du Parquet, Emmanuel Duguet, Yannick L'Horty, Pascale Petit

14-12. Residential discrimination and the ethnic origin: An experimental assessment in the Paris suburbs

Emmanuel Duguet, Yannick L'Horty, Pascale Petit

14-11. Discrimination based on place of residence and access to employment Mathieu Bunel, Yannick L'Horty, Pascale Petit

14-10. Rural Electrification and Household Labor Supply: Evidence from Nigeria Claire Salmon, Jeremy Tanguy

14-9. Effects of immigration in frictional labor markets: theory and empirical evidence from EU countries

Eva Moreno-Galbis, Ahmed Tritah

14-8. Health, Work and Working Conditions: A Review of the European Economic Literature

Thomas Barnay

14-7. Labour mobility and the informal sector in Algeria: a cross-sectional comparison (2007-2012)

Philippe Adair, Youghourta Bellache

14-6. Does care to dependent elderly people living at home increase their mental health? Thomas Barnay, Sandrine Juin

14_5. The Effect of Non-Work Related Health Events on Career Outcomes: An Evaluation in the French Labor Market

Emmanuel Duguet, Christine le Clainche

14_4. Retirement intentions in the presence of technological change: Theory and evidence from France

Pierre-Jean Messe, Eva Moreno - Galbis, Francois-Charles Wolff

14_3. Why is Old Workers' Labor Market more Volatile? Unemployment Fluctuations over the Life-Cycle

Jean-Olivier Hairault, François Langot, Thepthida Sopraseuth

14_2. Participation, Recruitment Selection, and the Minimum Wage

Frédéric Gavrel

14_1. Disparities in taking sick leave between sectors of activity in France: a longitudinal analysis of administrative data

Thomas Barnay, Sandrine Juin, Renaud Legal 
13_9. An evaluation of the impact of industrial restructuring on individual human capital accumulation in France (1956-1993)

Nicolas Fleury, Fabrice Gilles

13_8. On the value of partial commitment for cooperative investment in buyer-supplier relationship

José de Sousa, Xavier Fairise

13-7. Search frictions, real wage rigidities and the optimal design of unemployment insurance

Julien Albertini, Xavier Fairise

13-6. Tax me if you can! Optimal non linear income tax between competing governments Etienne Lehmann, Laurent Simula, Alain Trannoy

13-5. Beyond the labour income tax wedge: The unemployment-reducing effect of tax progressivity

Etienne Lehmann, Claudio Lucifora, Simone Moriconi, Bruno Van Der Linden

13-4. Discrimination based on place of residence and access to employment

Mathieu Bunel, Emilia Ene Jones, Yannick L'Horty, Pascale Petit

12-3. The determinants of job access channels: evidence from the youth labor market in Franc

Jihan Ghrairi

13-2. Capital mobility, search unemployment and labor market policies: The case of minimum wages

Frédéric Gavrel

13-1. Effort and monetary incentives in Nonprofit et For-Profit Organizations Joseph Lanfranchi, Mathieu Narcy 
The CNRS Institute for Labor Studies and Public Policies (the TEPP Institute, FR n ${ }^{\circ} 3435$ CNRS) gathers together research centres specializing in economics and sociology:

- L'Equipe de Recherche sur l'Utilisation des Données Individuelles en lien avec la Théorie Economique (Research Team on Use of Individuals Data in connection with economic theory), ERUDITE, University of Paris-Est Créteil and University of ParisEst Marne-la-Vallée

- Le Centre d'Etudes des Politiques Economiques de l'université d'Evry (Research Centre focused on the analysis of economic policy and its foundations and implications), EPEE, University of Evry Val d'Essonne

- Le Centre Pierre Naville (Research on Work and Urban Policies), CPN, University of Evry Val d'Essonne

- Le Groupe d'Analyse des Itinéraires et des Niveaux Salariaux (Group on Analysis of Wage Levels and Trajectories), GAINS, University of the Maine

- Le Centre de Recherches en Economie et en Management, (Research centre in Economics and Management), CREM, University of Rennes 1 et University of Caen Basse-Normandie

- Le Groupe de Recherche ANgevin en Économie et Management (Angevin Research Group in Economics and Management), GRANEM, University of Angers ;

- Le Centre de Recherche en Economie et Droit (Research centre in Economics and Law) CRED, University of Paris II Panthéon-Assas ;

- Le Laboratoire d'Economie et de Management Nantes-Atlantique (Laboratory of Economics and Management of Nantes-Atlantique) LEMNA, University of Nantes ;

- Le Laboratoire interdisciplinaire d'étude du politique Hannah Arendt - Paris Est, LIPHA-PE

- Le Centre d'Economie et de Management de l'Océan Indien, «CEMOI», équipe d'accueil $n^{\circ} E A 13$, rattachée à l'Université de la Réunion

The TEPP Institute brings together 200 researchers and research professors and $140 \mathrm{PhD}$ students who study changes in work and employment in relation to the choices made by firms and analyse public policies using new evaluation methods. 